\title{
REVIEW
}

\section{Clinical review: Humidifiers during non-invasive ventilation - key topics and practical implications}

\author{
Antonio M Esquinas Rodriguez ${ }^{*}$, Raffaele Scala², Arie Soroksky ${ }^{3}$, Ahmed BaHammam4, Alan de Klerk ${ }^{5}$, \\ Arschang Valipour ${ }^{6}$, Davide Chiumello ${ }^{7}$ Claude Martin ${ }^{8}$ and Anne E Holland ${ }^{9}$
}

\begin{abstract}
Inadequate gas conditioning during non-invasive ventilation (NIV) can impair the anatomy and function of nasal mucosa. The resulting symptoms may have a negative effect on patients' adherence to ventilatory treatment, especially for chronic use. Several parameters, mostly technical aspects of NIV, contribute to inefficient gas conditioning. Factors affecting airway humidity during NIV include inspiratory flow, inspiratory oxygen fraction, leaks, type of ventilator, interface used to deliver NIV, temperature and pressure of inhaled gas, and type of humidifier. The correct application of a humidification system may avoid the effects of NIV-induced drying of the airway. This brief review analyses the consequences of airway dryness in patients receiving NIV and the technical tools necessary to guarantee adequate gas conditioning during ventilatory treatment. Open questions remain about the timing of gas conditioning for acute or chronic settings, the choice and type of humidification device, the interaction between the humidifier and the underlying disease, and the effects of individual humidification systems on delivered humidity.
\end{abstract}

\section{Effects of inappropriate gas conditioning during non-invasive ventilation}

The human airway has an important role in heating and humidifying inspired gas, and recovering heat and moisture from expired gas. The amount of water vapor in a gas mixture can be measured as absolute humidity $(\mathrm{AH})$ or relative humidity $(\mathrm{RH})$ in relation to the temperature. $\mathrm{AH}$ is the total water present in the gas $\left(\mathrm{mg} \mathrm{H}_{2} \mathrm{O} / \mathrm{L}\right)$ and $\mathrm{RH}$ is the amount of water present expressed as the

\footnotetext{
*Correspondence: antmesquinas@gmail.com

'Intensive Care Unit, Hospital Morales Meseguer, Avenida Marqués de Los Velez s/n, 30500 Murcia, Spain

Full list of author information is available at the end of the article
}

percentage of maximum carrying capacity at a given temperature [1]. The human airway must provide gas at core temperature and $100 \% \mathrm{RH}$ at the alveolar surface in order to optimize gas exchange and protect lung tissue [2].

Non-invasive ventilation (NIV) is a mechanical ventilation modality that does not utilize an invasive artificial airway (endotracheal tube or tracheostomy tube) [3]. NIV is usually delivered through a nasal or oro-nasal mask so the inspired gas passes through the upper airway where it is conditioned. Like during spontaneous breathing, patients under NIV require adequate humidification and heating of the inspired air (that is, gas conditioning) [3]. NIV delivers inspired air at high flow rates, which may overwhelm the usual airway humidification mechanisms. Inadequate gas conditioning has been associated with anatomical and functional deterioration of nasal mucosa (ciliary activity, mucus secretion, local blood flow, nasal resistance). In addition, there are also negative effects on tolerance to NIV when a patient breathes inadequately humidified air [1,3-5] (Table 1).

Metaplastic changes and keratinization of the nasal epithelium and submucosa have been reported in patients on home-NIV when the level of humidification was inadequate for long periods [5]. These histopathological findings were confirmed by our recent survey, which found similar structural changes of the nasal mucosa in four patients with acute respiratory failure treated for 7 days with NIV without a humidification system added (unpublished data; Figure 1). This suggests that changes in the nasal mucosa occur relatively early after starting NIV in an acute setting and that humidification should be considered even when only short-term use of NIV is expected.

Inadequate airway gas conditioning may have serious consequences in critically ill patients using NIV $[6,7]$. Difficulties were recently reported with intubation in patients failing a trial of NIV delivered at high inspiratory oxygen fraction with a low level of humidification [6]. One case study showed ispissated secretions, causing life-threatening airway obstruction in a patient using NIV for hypoxemic respiratory failure [7]. A high fraction 
Table 1. Effects of inefficient gas conditioning during non-invasive ventilation

Increased nasal airway resistance

Structural and functional damage to nasal mucosa

Increased work of breathing

Difficulty in intubation

Discomfort and poor compliance to non-invasive ventilation

of inspired oxygen was also entrained into the NIV circuit and this extra anhydrous gas may have contributed to the airway obstruction.

Inadequate humidification can also cause significant discomfort for chronic NIV users. In an experimental setting, Wiest and colleagues [8] showed that drynessrelated symptoms started to appear when $\mathrm{AH}$ was lower than $15 \mathrm{mgH}_{2} \mathrm{O} / \mathrm{L}$. Normal subjects undergoing NIV without humidification scored discomfort significantly higher on a visual analogue scale than when heated humidification $(\mathrm{HH})$ was used, and this was associated with increased nasal airway resistance (NAWR). HH improved comfort and compliance to NIV $[6,9]$.

Similarly, Lellouche and colleagues [10], in healthy subjects under continuous positive airway pressure (CPAP) delivered by a bucco-nasal mask, found the level of comfort was significantly lower when no humidification was used. When a humidification device was applied and $\mathrm{AH}$ was higher than 10 to $12 \mathrm{mgH}_{2} \mathrm{O} / \mathrm{L}$ comfort was significantly better [10].

In a very comprehensive compliance analysis in patients in home-NIV, Nava and colleagues [11] compared two humidification systems, $\mathrm{HH}$ and a heat and moisture exchange filter (HME); compliance was much better ( $75 \%$ of patients) with the former. However, other symptoms, such as dry throat, the number of hospital admissions and the rate of complications caused by infection (mainly pneumonia), were similar with the two systems [11]. Similar results were published by Massie and colleagues [12], who stressed the importance of 'early' humidification from the very start of ventilatory treatment, so as to ensure the best possible compliance in home-NIV patients. Some other authors, however, maintain that humidification has no really significant effect on adherence to chronic NIV [13].

\section{Contributors to gas conditioning during non-invasive ventilation}

The optimal hygrometric values of $\mathrm{AH}$ or $\mathrm{RH}$ in the different NIV applications have not yet been established, since most data come from experimental studies that took direct (nasal cavities) or indirect (thermometers) measurements [14]. However, analysis of the need for humidification during NIV must clearly take account of the following parameters: 1) air leaks; 2) interface for

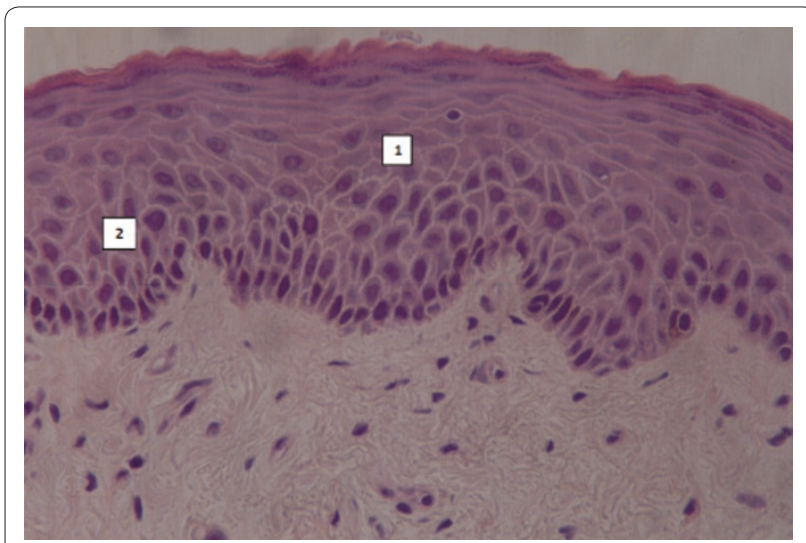

Figure 1. Biopsy of nasal mucosa. Metaplasia (1) and keratinization (2) in nasal respiratory mucosa in one patient without humidification during non-invasive ventilation.

NIV delivery; 3) type of ventilator; 4) room temperature; 5) temperatures of inhaled gas and the vaporization chamber; 6) airflow and pressure at the entrance of the humidification system; and 7) type of humidification system.

\section{Air leaks}

Mouth and/or peripheral mask air leaks, especially in tachypneic patients under NIV, cause unidirectional nasal air flow, so the mucosa recovers less heat and moisture during expiration. This may cause a continuous drop in AH. An increase in NAWR is the typical consequence of large mouth air leaks during NIV from a nasal mask. This reflects the nasal vasoconstrictive response to prolonged inhalation of dry air $[4,5]$. Clinically, increased NAWR is likely to lead to unsuccessful acclimatization to NIV in the chronic setting, and to the failure of NIV to improve gas exchange and dyspnea in the acute setting. Air leaks will also affect the performance of HMEs because the HME recovers less moisture when the expired air is drier.

The site of the leak, either unintentional (around the mask) or intentional (mask or circuit) also affects humidity. While the unintentional leaks are likely to have a substantial impact on AH because of the compensatory increase in inspiratory flow, the intentional leaks are not known to contribute to insufficient humidification of air during NIV. We can only speculate that inefficient washout of the exhaled air throughout an unintentional leak system (that is, plateau valve, anti-rebreathing valve) is likely to involve a substantial degree of humidity, especially in interfaces with high dead space, such as a total face mask.

In a study in adult volunteers, nasal CPAP with a mouth leak resulted in a three-fold increase in NAWR that was substantially attenuated by effective humidification [15]. 


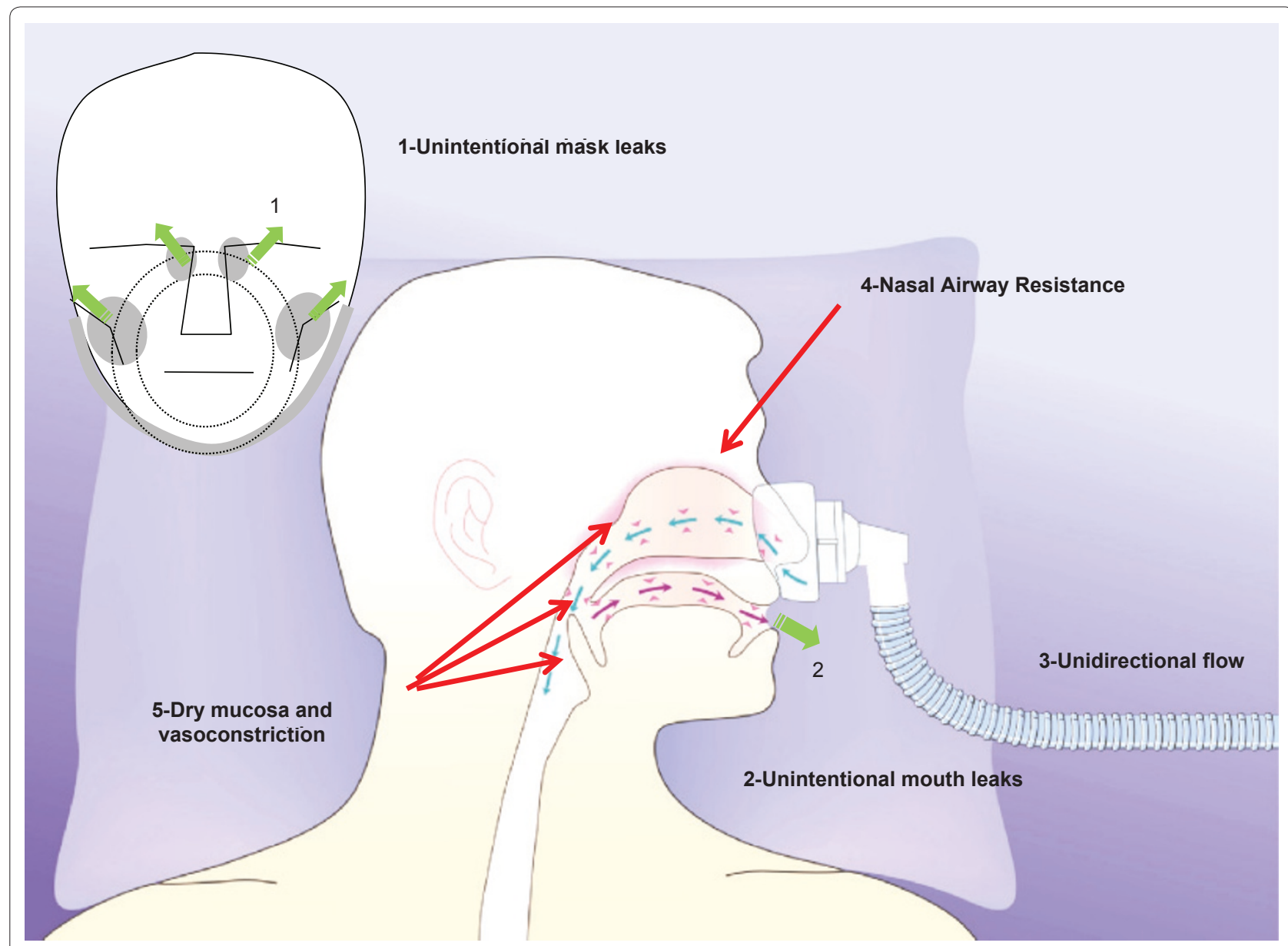

Figure 2. Pathophysiological effects of air leak on gas conditioning of the upper airways and its impact on nasal airway resistance and mucosa vasoconstriction.

These findings were confirmed in adult volunteers undergoing NIV [16]. This high NAWR would result in substantially lower effective pressure being transmitted to the nasopharynx and subsequently to the distal airway (Figure 2).

\section{Interfaces}

The most common interfaces used to deliver NIV are nasal and facial masks, the former being tolerated better in the chronic than the acute setting. However, nasal masks tend to have more leaks than face masks, and this can result in inadequate gas conditioning of inspired air. The use of an oro-nasal mask avoids the changes in $\mathrm{RH}$ related to mouth leaks [17]. This choice is likely to be crucial to the success of NIV in selected categories of acute patients (for example, need for prolonged ventilatory support, difficulty in spontaneously clearing secretions, mouth-breathers) $[18,19]$.

Physicians using the helmet to deliver NIV must be particularly careful. Compared to the other more popular interfaces (nasal, oro-nasal, total face masks), the helmet has a much larger inner space (more than 10 liters), which may act as a 'reservoir' of humidity because of the amount of exhaled gas that remains there [19]. The clinician must therefore carefully adjust the humidification of the inhaled gas depending on the type of interface and the resulting leak pattern.

\section{Ventilator types}

Intensive care ventilators, home-care mechanical ventilators, and high-flow CPAP systems operate by providing a very high inspiratory flow to compensate for the inspiratory demand of a patient with acute respiratory failure and the air leaks when applied in a NIV mode. This issue was originally studied by Poulton and Downs [20] with high airflow CPAP systems delivered with a non-invasive interface.

The technical aspects are more sophisticated for the different NIV equipment introduced in the last few decades. The impact on humidification depends on the 
type of ventilator used in acute and chronic settings. Single-circuit home ventilators and/or dedicated NIV ventilators equipped with a turbine or piston differ from double-circuit ICU ventilators, which are pneumatic and supplied with high-pressure sources of gas. Home models - that is, blower-based devices - compress room air and have higher humidity than ICU ventilators, which obtain dry gas directly from a mains hospital outlet. This was clearly depicted by Wiest and colleagues [21], who demonstrated that ICU ventilators provided a lower level of AH during NIV than turbine mechanical ventilators (5 versus $13 \mathrm{mgH}_{2} \mathrm{O} / \mathrm{L}$ ) [21]. Here we have to bear in mind that $\mathrm{AH}$ lower than $5 \mathrm{mgH}_{2} \mathrm{O} / \mathrm{L}$ is 'critical' for the likelihood of complications related to inadequate gas conditioning of inspired air [21].

Given the decrease in humidity resulting from the anhydrous nature of medical oxygen, physicians have also to remember that the higher the oxygen fraction delivered during NIV, the greater the risk of inadequate gas conditioning without the addition of $\mathrm{HH}$ or a HME.

Chiumello and colleagues [22] compared the hygrometric values in a helmet system during CPAP with or without $\mathrm{HH}$, delivered by either a mechanical ventilator or a continuous low $(40 \mathrm{~L} /$ minute) or high $(80 \mathrm{~L} /$ minute $)$ flow CPAP, in nine patients with acute respiratory failure and ten healthy subjects. The $\mathrm{HH}$ system raised the $\mathrm{AH}$ during ventilator CPAP (from $18.4 \pm 5.5 \mathrm{mgH}_{2} \mathrm{O} / \mathrm{L}$ to $34.1 \pm 2.8 \mathrm{mgH}_{2} \mathrm{O} / \mathrm{L}$ ) and with CPAP at low flow (from $11.4 \pm 4.8 \mathrm{mgH}_{2} \mathrm{O} / \mathrm{L}$ to $33.9 \pm 1.9 \mathrm{mgH}_{2} \mathrm{O} / \mathrm{L}$ ) and with CPAP at high flow (from $6.4 \pm 1.8 \mathrm{mgH}_{2} \mathrm{O} / \mathrm{L}$ to $24.2 \pm 5.4 \mathrm{mgH}_{2} \mathrm{O} / \mathrm{L}$ ). Without $\mathrm{HH}$, the $\mathrm{AH}$ was significantly higher with ventilator CPAP than with the continuous low flow and high flow. The level of comfort was similar for all three modalities, with or without the $\mathrm{HH}$. The findings in healthy individuals were similar to those in patients with acute respiratory failure.

\section{Ambient temperature}

Even though insufficient humidification during NIV can be caused by specific climatic or environmental conditions in the place where the treatment is implemented (for example, an excessively cold sleeping area), the majority of cases suffering from excessive airway dryness are due to technical factors related to the ventilation process itself and its interaction with the patient (interface, leaks, inspired oxygen fraction, respiratory rate, use of humidifiers). The effects of ambient temperature probably only need be considered for patients who sleep in very cold premises.

\section{Temperature of the inhaled gas}

Conditioning inspired gas involves both heating and humidification. To facilitate gas exchange and protect lung tissue, inspired gas must reach body temperature by the time it arrives at the alveolar surface [23]. How easily this can be achieved depends on the temperature of the inhaled gas. The ventilator power source affects gas temperature, as turbine-driven systems create more heat than piston-driven ventilators. Increasing levels of inspiratory positive airway pressure (IPAP) have also been reported to raise the gas temperature with a turbine-driven NIV device [24]. This tended to preserve $\mathrm{AH}$ at high IPAP levels, but it was not sufficient to maintain adequate humidity when ambient $\mathrm{RH}$ was low. In this bench study, $\mathrm{HH}$ set at its highest temperature was most effective in countering the deleterious effects of NIV on delivered humidity. In clinical practice the temperature setting for $\mathrm{HH}$ may be based on the patient's tolerance.

\section{Airflow at the entrance to the humidifier}

The impact of the airflow entering the HH humidification chamber is one of the most important physical phenomena affecting airway humidity. This was largely studied by Wenzel and colleagues [25], who analyzed the factors underlying humidification capacity over a variable range of airflows at the entrance to the humidification chamber (20, 55, and $90 \mathrm{~L} /$ minute). At high flow rates, many commercial humidifiers were unable to generate adequate RH. Clinically, this suggests that a humidifier alone may not be enough to ensure adequate humidification of inspired gases, particularly at high flow rates [26].

\section{Types of humidification system}

In general, $\mathrm{HH}$ and $\mathrm{HME}$ technically produce similar $\mathrm{AH}$ levels ( 25 to $30 \mathrm{mgH}_{2} \mathrm{O} / \mathrm{L}$ ), which are adequate for the physiological functioning of the upper airway. However, the gas conditioning performance of each system may vary over a range of respiratory rates, especially at the ventilator airflow that enters the system through the humidification chamber $[18,27,28]$.

The choice of active HH or HME may have repercussions on respiratory mechanics - such as tidal volume, minute volume, and work of breathing - and gas exchange $[29,30]$. For NIV, significant disadvantages have been observed with the HME compared to the $\mathrm{HH}$ (Table 2). HMEs have been associated with greater dead space and possibly also $\mathrm{CO}_{2}$ retention. This was shown by Jaber and colleagues [29], who reported higher partial pressure of arterial carbon dioxide $\left(\mathrm{PaCO}_{2}\right)$ during NIV with HME than with HH. Similarly, Lellouche and colleagues [30] found inspiratory effort was greater in patients with hypercapnia during HME than $\mathrm{HH}$. This has also been associated with increased work of breathing. On the basis of these studies, therefore, it would seem that $\mathrm{HH}$ is superior to HME during acute NIV but this advantage is probably limited to acute rather than chronic settings. 
Table 2. Advantages and disadvantages of heat and moisture exchanger filter and heated humidifier systems during non-invasive ventilation

\begin{tabular}{|c|c|c|}
\hline System & Advantages & Disadvantages \\
\hline \multirow[t]{6}{*}{ HME } & Cost effective & Increased dead space \\
\hline & Extended use in the ICU & Reduced efficacy in case of leaks \\
\hline & \multirow{2}{*}{$\begin{array}{l}\text { Eliminates circuit condensation (hygroscopic models are } \\
\text { recommended) }\end{array}$} & Efficacy depends on body and environmental temperatures \\
\hline & & \multirow{3}{*}{$\begin{array}{l}\text { May lead to an increase in airway resistance in patients with heavy secretions } \\
\text { and respiratory tract bleeding }\end{array}$} \\
\hline & $\begin{array}{l}\text { A booster system applied to a hydrophobic HME may preserve } \\
\text { AH capacity when incoming gases are delivered at a temperature } \\
\text { lower than } 26^{\circ} \mathrm{C} \text { and at high flow }\end{array}$ & \\
\hline & Does not need electricity & \\
\hline \multirow[t]{4}{*}{$\mathrm{HH}$} & Less work of breathing than with HME & Less efficacy with high environmental temperature \\
\hline & \multirow{2}{*}{$\begin{array}{l}\text { Limited or no effect on dead space ventilation so } \mathrm{CO}_{2} \text { retention is } \\
\text { minimal }\end{array}$} & Needs electricity \\
\hline & & \multirow[t]{2}{*}{ Performance of different devices varies } \\
\hline & $\begin{array}{l}\text { Clinically effective, especially in patients with mild to severe } \\
\text { hypercapnic acute respiratory failure }\end{array}$ & \\
\hline
\end{tabular}

$\mathrm{AH}$, absolute humidity; $\mathrm{HH}$, heated humidifier; $\mathrm{HME}$, heat and moisture exchanger filter; $\mathrm{RH}$, relative humidity.

The choice of the humidifier for NIV must also take into consideration the interface, and the amount of unintentional leaks. In the absence of substantial leaks, the AH was no different with $\mathrm{HH}$ or HME when using a face mask during NIV [10]. However, when there were excessive leaks the AH significantly dropped when using HME (around 40\%). The leak affects the HME's performance by changing the difference between inspired volume (cool air) and expired volume (warm, moist air).

In their bench study, Holland and colleagues [31] examined the effects of mechanical ventilation parameters on $\mathrm{RH}$ and $\mathrm{AH}$, and the effect of a $\mathrm{HH}$ system on $\mathrm{RH}, \mathrm{AH}$, and ventilator performance during NIV. Without humidification, RH in the NIV circuit (range 16.3 to 26.5\%) was substantially lower than the ambient RH (27.6 to $31.5 \%)$ at all ventilatory settings. Increasing the IPAP led to a significant decrease in RH (Spearman's rho $=$ $0.67, P<0.001$ ), which returned to normal when $\mathrm{HH}$ was applied. Changing the respiratory rate or inspiratoryexpiratory ratio had no significant effect. $\mathrm{RH}$ and $\mathrm{AH}$ both rose with the addition of humidification, and the air was fully saturated at the maximum heater setting. A key conclusion of this study was therefore that the incorporation of HH systems in NIV ventilators increased the RH.

Esquinas and colleagues [32] analyzed $\mathrm{AH}$ values in a series of patients with hypoxemic acute respiratory failure, with NIV administered by a turbine-driven ventilator and a face mask, over a wide range of inspired oxygen fractions in four different NIV environments: 1) without humidification; 2) with a HH-MR850; 3) with a HH730; 4) with a HME booster. The main findings were that the increase in inspired oxygen fraction led to a proportional decrease in $\mathrm{AH}$ and this effect was greater in an environment without humidification than during NIV delivered with $\mathrm{HH}$ and HME-booster systems, and that $\mathrm{AH}$ levels were 'critical' when the inspired oxygen fraction was higher than 60\% [32].

In agreement with Holland and colleagues [31], Esquinas and colleagues [32] found $\mathrm{AH}$ was higher with a humidification system. When $\mathrm{HH}$ and HME booster systems were compared, AH was higher with the latter; however, the HME booster caused more patient-ventilator asynchrony and hypercapnia.

There is as yet no uniform recommendation for any one device and there is also only limited epidemiological information on the best hospital practices and protocols for humidification and device selection. Recently, our international group for the study of humidification (the Humivenis Working Group) carried out a survey in 15 units with NIV expertise and found that usual practice was to use $\mathrm{HH}$ more often than HME for acute NIV applications (53\% versus 6.6\%). Surprisingly, despite the importance of gas conditioning during NIV, there were relatively few hospital protocols referring to humidification practice in the participating centers (55\%) [6].

\section{Humidification and CPAP therapy in patients with obstructive sleep apnea}

Obstructive sleep apnea (OSA) is one of the most important indications for chronic use of CPAP at home. CPAP therapy is the gold standard for OSA patients and compliance with therapy reduces morbidity and mortality [33]. Nevertheless, compliance and adherence to CPAP for OSA patients remains a major problem. The most frequently reported factors associated with low acceptance and adherence rates include side effects such as nasal congestion, dry nose or throat, discomfort related 
to cold air, and/or allergy to the interface material; these are reported by as many as $65 \%$ of patients using nasal CPAP [34]. Chronic nasal congestion in particular can compromise a patient's ability to use CPAP successfully.

The nasal mucosa has a considerable capacity for heating and humidifying inspired air but even so it can be overwhelmed at high flow rates with CPAP and when there is unidirectional flow caused, for instance, by mouth leaks. The flow of cold air through the nose dries the mucosa, resulting in the release of vasoactive and proinflammatory mediators. These boost superficial mucosal blood flow and cause engorgement of deeper capacitance vessels, leading to increased nasal resistance. This in turn promotes mouth breathing, setting up a vicious circle.

These complications can be largely prevented by humidifying the inspired air. Most current CPAP devices come with an integrated $\mathrm{HH}$ system. As these deliver more moisture than cold pass-over humidifiers they may be more effective in patients with mouth leak and nasal congestion [12].

$\mathrm{HH}$ reduces nasal symptoms and nasal resistance, consequently attenuating inflammatory cell infiltration and fibrosis of the nasal mucosa $[35,36]$. Therefore, the American Academy of Sleep Medicine has recommended the use of $\mathrm{HH}$ to improve CPAP compliance and adherence as a standard of practice [37]. According to the scientific literature, however, $\mathrm{HH}$ should only be added when patients complain of bothersome upper airway symptoms that are unresponsive to simpler measures (for example, intranasal steroids, temporary use of local vasoconstrictors) as there is no reliable information on the improvements in CPAP acceptance, adherence, or quality of life resulting from 'prophylactic' humidification $[36,38]$.

\section{Conclusion}

During NIV, adequate gas conditioning is essential because of the deleterious effects of inhalation of dry air, which may then negatively influence adherence to and the success of the ventilatory treatment. Several parameters, mostly involving the technical aspects of NIV, are determinants of inefficient humidification. The correct application of an appropriate humidification system may help prevent NIV-induced airway dryness. However, there are still open questions about when exactly to apply a humidifier in acute or chronic settings, the best type of humidification device in each situation, the interaction between the humidifier and the underlying disease and the effects of individual ventilators on delivered humidity.

\section{Abbreviations}

$\mathrm{AH}$, absolute humidity; CPAP, continuous positive airway pressure; $\mathrm{HH}$, heated humidifier; $\mathrm{HME}$, heat and moisture exchanger filter; IPAP, inspiratory positive airway pressure; NAWR, nasal airway resistance; NIV, non-invasive ventilation; OSA, obstructive sleep apnea; RH, relative humidity.

\section{Competing interests}

All authors declare they have no competing interests or financial competing interests (political, personal, religious, ideological, academic, intellectual, commercial or any other) in relation to this manuscript.

\section{Acknowledgements}

All authors declare they have not received any funding in study design; in data collection, analysis, and interpretation; in writing the manuscript; and in the decision to submit the manuscript for publication.

\section{Author details}

${ }^{1}$ Intensive Care Unit, Hospital Morales Meseguer, Avenida Marqués de Los Velez s/n, 30500 Murcia, Spain. ${ }^{2}$ UO PNEUMOLOGIA, UTIR, Interventistica, Ospedale Campo di Marte, Lucca, Italy. ${ }^{3}$ E. Wolfson Medical Center, Hulon, Israel. ${ }^{4}$ University Sleep Disorders Center, College of Medicine, King Saud University, Riyadh, Saudi Arabia. ${ }^{5}$ Department of Neonatology/BirthCare Center, Florida Hospital Memorial Medical Center, Daytona Beach, FL 32117, USA. ${ }^{6}$ Department of Respiratory and Critical Care Medicine, LudwigBoltzmann-Institute for COPD and Respiratory Epidemiology, Otto-WagnerSpital, Sanatoriumstr. 2, 1140 Wien, Austria. ${ }^{7}$ Dipartimento di Anestesia, Rianimazione e Terapia del Dolore, Fondazione IRCCS Cà Granda- Ospedale Maggiore Policlinico, Via F. Sforza 35, Milan, Italy. ${ }^{8}$ Service d'AnesthésieRéanimation, Hôpital Nord - 13915, Marseille cedex 20, France. 'a Trobe University/Alfred Health, Level 4, The Alfred Centre, 99 Commercial Rd, 3004 Melbourne, Australia.

Published: 8 February 2012

\section{References}

1. Shelly MP, Lloyd GM, Park GR: A review of the mechanisms and methods of humidification of inspired gases. Intensive Care Med 1988, 14:1-9.

2. Williams R, Rankin N, Smith T, Galler D, Seakins P: Relationship between the humidity and temperature of inspired gas and the function of the airway mucosa. Crit Care Med 1996, 24:1920-1929.

3. Evans TW: International Consensus Conferences in Intensive Care Medicine: non-invasive positive pressure ventilation in acute respiratory failure. Organised jointly by the American Thoracic Society, the European Respiratory Society, the European Society of Intensive Care Medicine, and the Societe de Reanimation de Langue Francaise, and approved by the ATS Board of Directors, December 2000. Intensive Care Med 2001, 27:166-178.

4. Esquinas A, Escobar C, Chavez A, Picazos C: Noninvasive mechanical ventilation and humidification in acute respiratory failure. a morpho histological and clinical study of side effects. Am J Respir Crit Care Med 2002, 165:A385.

5. Hayes MJ, McGregor FB, Roberts DN, Schroter RC, Pride NB: Continuous nasal positive airway pressure with a mouth leak: effect on nasal mucosal blood flux and nasal geometry. Thorax 1995, 50:1179-1182.

6. Esquinas A, Nava S, Scala R, Carrillo A, Gonzalés G, Humivenis Working Group: Humidification and difficult endotracheal intubation in failure of noninvasive mechanical ventilation (NIV). Preliminary results. Am J Respir Crit Care Med 2008, 177:A644.

7. Wood KE, Flaten AL, Backes WJ: Inspissated secretions: a life-threatening complication of prolonged noninvasive ventilation. Respir Care 2000, 45:491-493.

8. Wiest GH, Foerst J, Fuchs FS, Schmelzer AH, Hahn EG, Ficker JH: In vivo efficacy of two heated humidifiers used during CPAP-therapy for obstructive sleep apnea under various environmental conditions. Sleep 2001, 24:435-440.

9. Tuggey JM, Delmastro M, Elliott MW: The effect of mouth leak and humidification during nasal non-invasive ventilation. Respir Med 2007 101:1874-1879.

10. Lellouche F, Maggiore SM, Lyazidi A, Deye N, Taille S, Brochard L: Water content of delivered gases during non-invasive ventilation in healthy subjects. Intensive Care Med 2009, 35:987-995.

11. Nava S, Cirio S, Fanfulla F, Carlucci A, Navarra A, Negri A, Ceriana P: Comparison of two humidification systems for long-term noninvasive mechanical ventilation. Eur Respir J 2008, 32:460-464.

12. Massie CA, Hart RW, Peralez K, Richards GN: Effects of humidification on nasal symptoms and compliance in sleep apnea patients using continuous positive airway pressure. Chest 1999, 116:403-408. 
13. Mador MJ, Krauza M, Pervez A, Pierce D, Braun M: Effect of heated humidification on compliance and quality of life in patients with sleep apnea using nasal continuous positive airway pressure. Chest 2005, 128:2151-2158

14. Fischer $Y$, Keck T, Leiacker R, Rozsasi A, Rettinger G, Gruen PM: Effects of nasal mask leak and heated humidification on nasal mucosa in the therapy with nasal continuous positive airway pressure (nCPAP). Sleep Breath 2008, 12:353-357

15. Richards GN, Cistulli PA, Ungar RG, Berthon-Jones M, Sullivan CE: Mouth leak with nasal continuous positive airway pressure increases nasal airway resistance. Am J Respir Crit Care Med 1996, 154:182-186.

16. Carrey Z, Gottfried SB, Levy RD: Ventilatory muscle support in respiratory failure with nasal positive pressure ventilation. Chest 1990, 97:150-158.

17. Hoffstein V, Viner S, Mateika S, Conway J: Treatment of obstructive sleep apnea with nasal continuous positive airway pressure. Patient compliance, perception of benefits, and side effects. Am Rev Respir Dis 1992 145:841-845.

18. Chiumello D, Gattinoni L, Pelosi P: Conditioning of inspired gases in mechanically ventilated patients. In Yearbook of Intensive Care and Emergency 2002. Edited by Vincent JL. Springer; 2002:275-286.

19. Crimi C, Noto A, Princi P, Nava S: Survey of non-invasive ventilation practices: a snapshot of Italian practice. Minerva Anestesio/ 2010 77:971-978.

20. Poulton TJ, Downs JB: Humidification of rapidly flowing gas. Crit Care Med 1981, 9:59-63.

21. Wiest GH, Fuchs FS, BrueckI WM, Nusko G, Harsch IA, Hahn EG, Ficker JH: In vivo efficacy of heated and non-heated humidifiers during nasal continuous positive airway pressure (nCPAP)-therapy for obstructive sleep apnoea. Respir Med 2000, 94:364-368.

22. Chiumello D, Chierichetti M, Tallarini F, Cozzi P, Cressoni M, Polli F, Colombo R, Castelli A, Gattinoni L: Effect of a heated humidifier during continuous positive airway pressure delivered by a helmet. Crit Care 2008, 12:R55.

23. Severgnini P, D'Onofrio D, Frigerio A, Apostolou G, Chiumello D, LiBassi G, Storelli E, Pelosi P, Chiaranda M: [A rationale basis for airways conditioning: too wet or not too wet? ]. Minerva Anestesio/ 2003, 69:297-301.

24. Sanders MH, Gruendl CA, Rogers RM: Patient compliance with nasal CPAP therapy for sleep apnea. Chest 1986, 90:330-333.

25. Wenzel M, Wenzel G, Klauke M, Kerl J, Hund-Rinke K: [Characteristics of several humidifiers for CPAP-therapy, invasive and non-invasive ventilation and oxygen therapy under standardised climatic conditions in a climatic chamber]. Pneumologie 2008, 62:324-329.

26. Poulton TJ, Downs JB: Humidification of rapidly flowing gas. Crit Care Med 1981, 9:59-63.

27. Branson RD: Humidification for pateints with artificial airways. Respir Care 1999, 44:630-642.
28. Schumann S, Stahl CA, Moller K, Priebe HJ, Guttmann J: Moisturizing and mechanical characteristics of a new counter-flow type heated humidifier. Br J Anaesth 2007, 98:531-538.

29. Jaber S, Chanques G, Matecki S, Ramonatxo M, Souche B, Perrigault PF, Eledjam JJ: Comparison of the effects of heat and moisture exchangers and heated humidifiers on ventilation and gas exchange during noninvasive ventilation. Intensive Care Med 2002, 28:1590-1594.

30. Lellouche F, Maggiore SM, Deye N, Taille S, Pigeot J, Harf A, Brochard L: Effect of the humidification device on the work of breathing during noninvasive ventilation. Intensive Care Med 2002, 28:1582-1589.

31. Holland AE, Denehy L, Buchan CA, Wilson JW: Efficacy of a heated passover humidifier during noninvasive ventilation: a bench study. Respir Care 2007 52:38-44.

32. Esquinas A, Carrillo A, Gonzalés G, Humivenis Working Group: Absolute humidity variations with a variable inspiratory oxygenation fraction in noninvasive mechanical ventilation. A pilot study. Am J Respir Crit Care Med 2008, 177:A644.

33. Selim B, Won C, Yaggi HK: Cardiovascular consequences of sleep apnea. Clin Chest Med 2010, 31:203-220.

34. Pepin JL, Leger P, Veale D, Langevin B, Robert D, Levy P: Side effects of nasal continuous positive airway pressure in sleep apnea syndrome. Study of 193 patients in two French sleep centers. Chest 1995, 107:375-381.

35. Koutsourelakis I, Vagiakis E, Perraki E, Karatza M, Magkou C, Kopaka M, Roussos C, Zakynthinos S: Nasal inflammation in sleep apnoea patients using CPAP and effect of heated humidification. Eur Respir J 2011, 37:587-594.

36. Ryan S, Doherty LS, Nolan GM, McNicholas WT: Effects of heated humidification and topical steroids on compliance, nasal symptoms, and quality of life in patients with obstructive sleep apnea syndrome using nasal continuous positive airway pressure. J Clin Sleep Med 2009, 5:422-427.

37. Kushida CA, Littner MR, Hirshkowitz M, Morgenthaler TI, Alessi CA, Bailey D, Boehlecke B, Brown TM, Coleman J Jr, Friedman L, Kapen S, Kapur VK, Kramer M, Lee-Chiong T, Owens J, Pancer JP, Swick TJ, Wise MS; American Academy of Sleep Medicine: Practice parameters for the use of continuous and bilevel positive airway pressure devices to treat adult patients with sleep-related breathing disorders. Sleep 2006, 29:375-380.

38. Duong M, Jayaram L, Camfferman D, Catcheside P, Mykytyn I, McEvoy RD: Use of heated humidification during nasal CPAP titration in obstructive sleep apnoea syndrome. Eur Respir J 2005, 26:679-685.

doi:10.1186/cc10534

Cite this article as: Esquinas Rodriguez AM, et al:: Clinical review: Humidifiers during non-invasive ventilation - key topics and practical implications. Critical Care 2012, 16:203. 